\section{Doing good}

Social change initiatives and ethical thinking

Social change is complex.
Program designers and
implementers need to deal
with complexity in ethical ways.
Ms Susan Igras and Dr Anjalee
Kohli at Georgetown University
and their co-authors examine
the power dynamics of norms-
shifting interventions in fostering
health himprovement. Their
aim is to develop an approach
to designing and carrying
out interventions which more
systematically take into account
values, power differentials, and
needs of local populations and
organizations. They advocate for
systematising ethical thinking
in partnerships and dialogues
between NGOS, communities,
and external organizations.

Social norms are everywhere, believe are desirable and expected

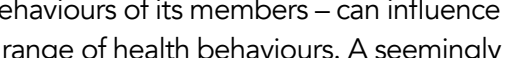
a range of health behaviours. A seemingly simple program promoting an uptake of
the Covid-19 vaccine reveals normative the Covid-19 vaccine reveals norm
issues requiring ethical decisionissues requiring ethical decision-
making. For example, as a designer making. For example, as a designer prioritize for vaccines in the midst of pandemic - the elderly or school aged children? People living in urban or in rura communities? At the level of program implementation, how do you convince groups who are hesitating to get the vaccine, and how to you mitigate public opposition that might emerge? Although there is often no 'right' answer - decisionmaking in health promotion projects is complex - ethical thinking can help to clarify decisions in ways that respect community beliefs and achieve public health aims.

One overarching goal of norms-shifting

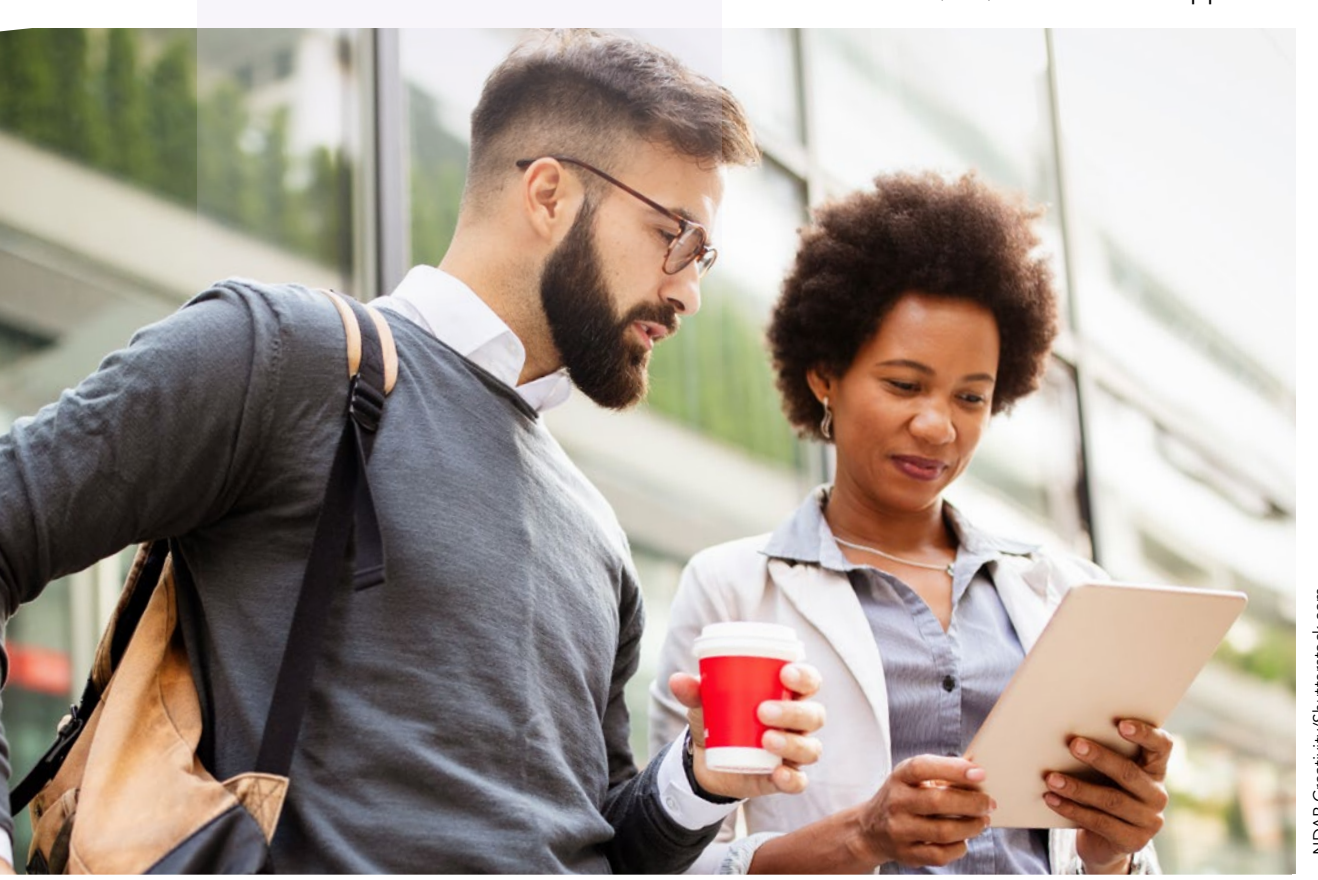

normative environment that enables mproved health and well-being (Legros \& Cislaghi, 2020; Mackie et al., 2015; Miller \& Prentice, 2016). Community-based NS aim to foster change through community dialogues that support new normative posibities as part of social and behavio

NSI are often carried out by rganizations who are not intimately familiar with the socio-cultural and

they affect. Yet, these organizations and individuals may be responsible for or part of teams that design and implement interventions for communities. This distance between organizations external to communities local organizations and communities is a barrier to socia change and improved normative environments. All communities have their own complex histories that mould their societies. Communities include a diverse mix of stakeholders, who have different economic, social, gender, and age backgrounds. Power dynamics within and between organizations has voice and choice, how decisions are made and whose values and perspectives are given importance. Even when not explicitly stated, values and assumptions are guiding the process of NSI design and implementation, and perhaps not in the way people think.

In their paper, Ms Susan Igras, Dr Anjalee Kohli and co-authors critically reflect on the ethical considerations that should be (n)

\section{ETHICAL CONSIDERATions} AND SOCIAL ISSUES AND SOCIAL ISSUES In order to gain a better understanding Kohli, and their cot Nit can cause, Igras, Tier reviewed 125 articles on ethical

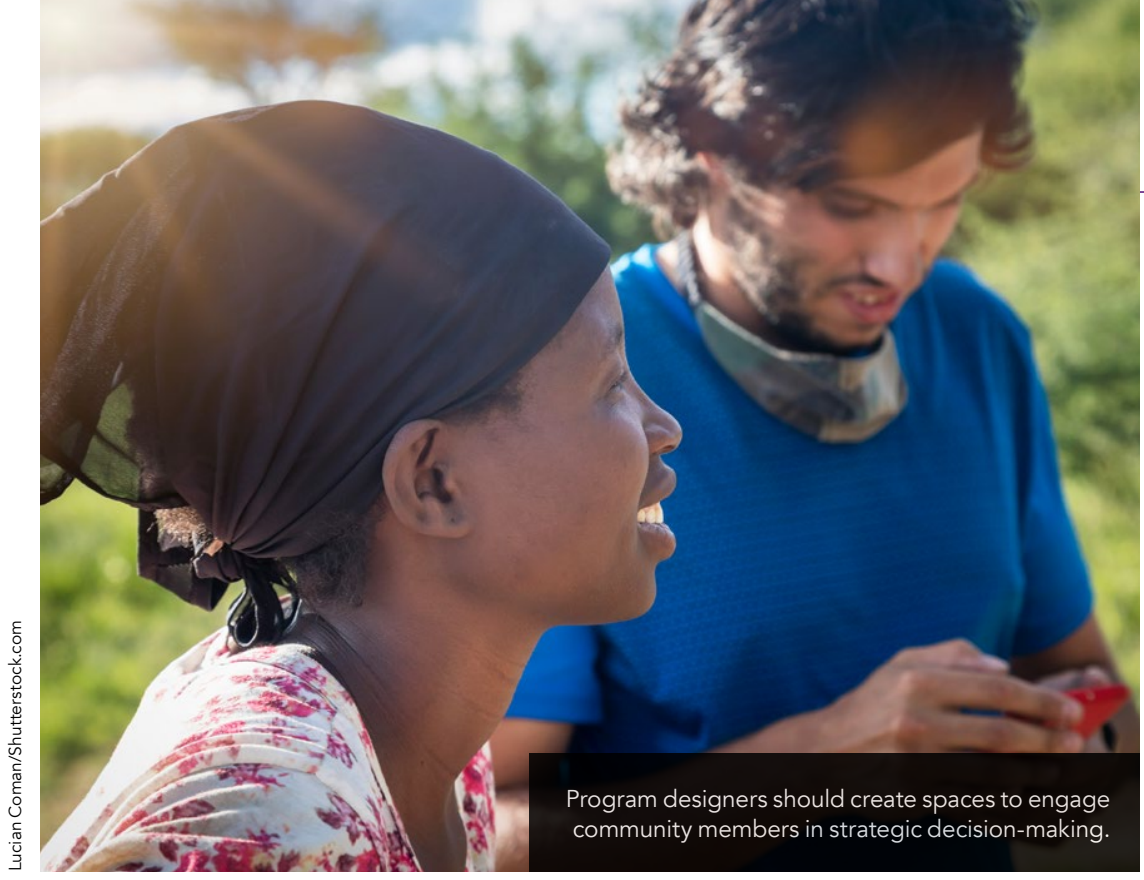

considerations in public health, social These issues also arise and are justice, and human rights. They aimed at pointing to the gaps in existing important to the relationships between external organizations seeking to make to guide engagement with people and and communities. To this end, the communities. The

first five values
-inclusiveness,

openness,

reasonableness,

responsiveness, and

responsibleness -

relate to the NSI program design

The process

of implementation should involve minimising harm, respect, fairness,

solidarity, and reciprocity. Keeping tha

in mind, all 10 values can be applied at

any stage of a project.

NSI work at multiple levels, even when they primarily focus on the community strategies. NSt seek social change for trying to place NSI designers and local community on an equal footing. Yet relationships between Global North implementers and program designers with Global South organizations do not typically play out this way. Instead, unequal power dynamics as seen in organizational funding and decisionmaking power, for example, have roots in colonialism and other historical forces. Global North organizations, knowingly or not, impose their own way of thinking on the Global South communities. It is important to make sure that unequal power relations are replaced by mor equitable relationships.

NSI seek social change for greater

making decisions or taking actions that are (thical" "Thornton, 2019). Ethical thinking (Fawcett 1991) in papticular using values to inform how we make decisions and what decisions we make. In this respect the authors argue that NSI interact with many actors and groups. NSI aims and strategies can be interpreted through different value systems by communities and outsider organizations, and different social groups within communities.

THE HYBRIDITY APPROACH People designing NSI interventions should be aware that there are different sets of values that should be accounted TGOs is a danger that Global North lesign inther financed organizations design interventions through their own culcrall lenses, without considering the populations and populations and organizations and
how these views how these views focus and strategies. organizations work context. Even if they on an equal footing.

researchers highlight the importance of ethical thinking, seen as "the process of analysing and understanding multiple rather than improve community inequities cond a changing context AND applying ethical values to make work to understand issues clearly before

Dialogue and negotiation with community stakeholders is the foundation of a hybridity approach. The team suggest
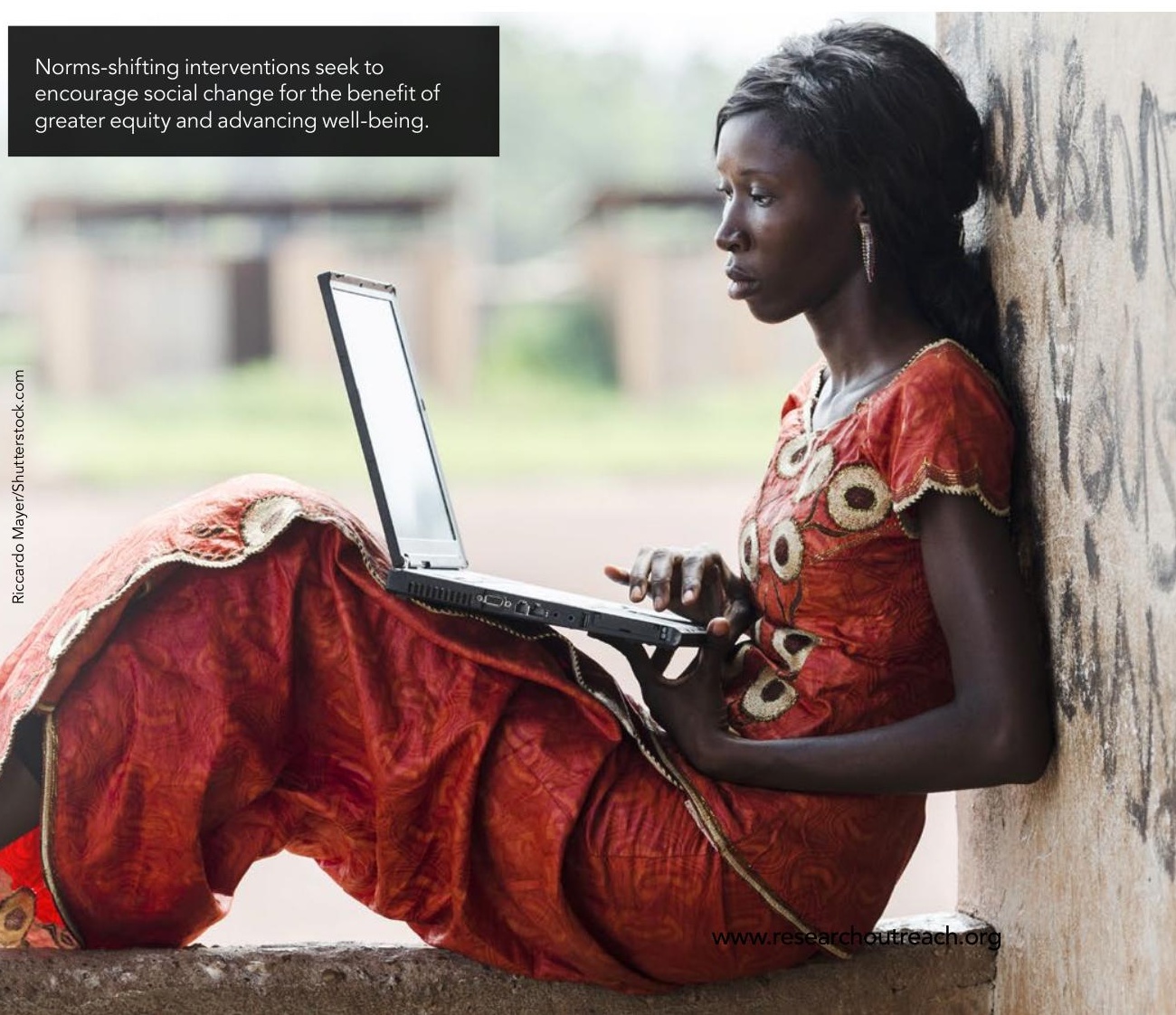


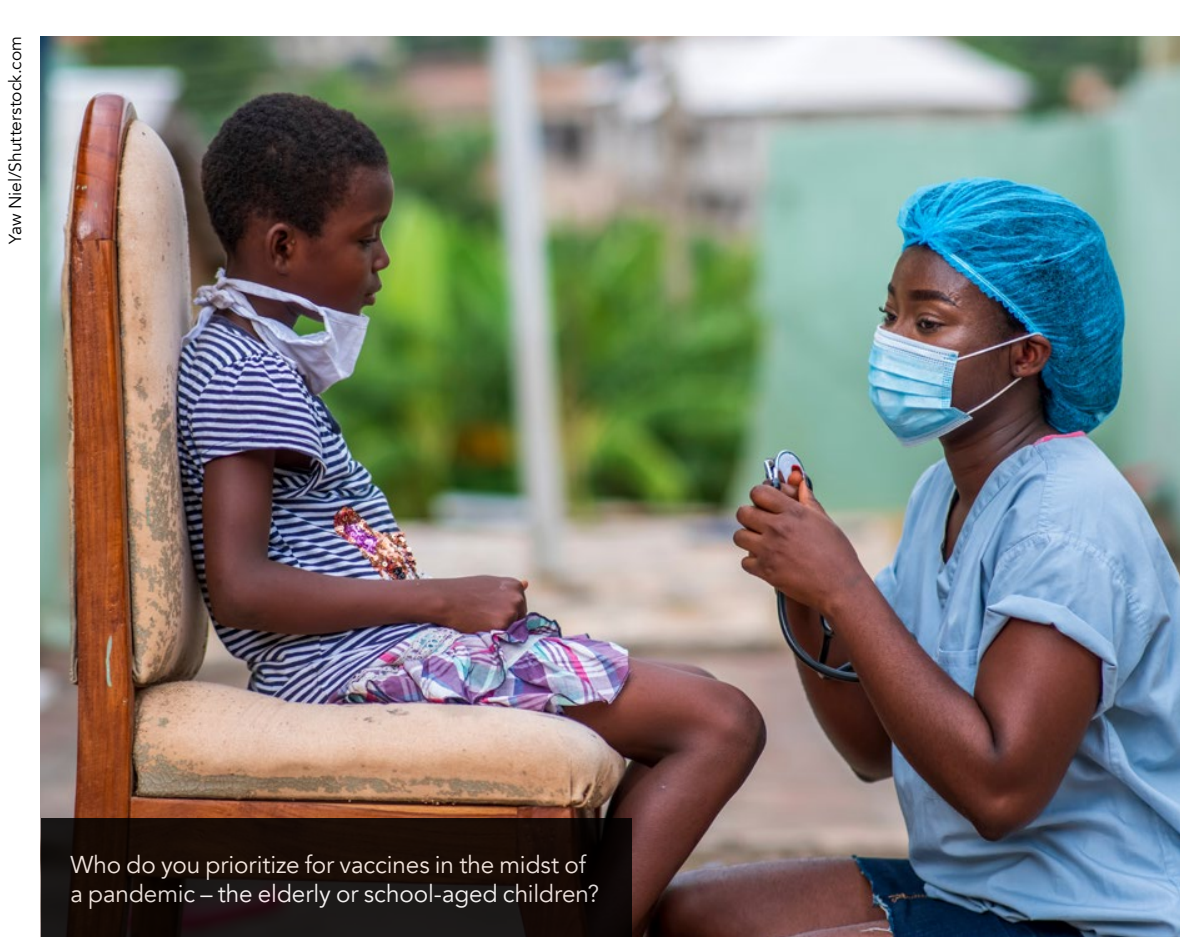

organizing transportation for the elderly to go to vaccination sites. These are social change efforts begin. Health promotion projects need to anticipate, monitor and be ready to respond to pushback and support community or individual early adopters of change. The inclusion of ethical thinking based on common values should occur more systematically in both project design and implementation phases.

Project staff should conduct regular follow-ups between project staff,

frontine workers, and other community stakeholders on how the interventions are progressing, and obtain regular feedback through the meetings organized. As the set of values can guide what ding a shared set of values can guide what decisions are made vis-a-vis emerging social changes

a diversity in value systems and values held at the individual, community and discussing and stating values and appreciating different value systems $c$ be used to build partnerships and guide discussions and decision-making for NSI design and implementation. Without structured reflection and partnership and programming grounded in values, this leads to situations where Global North NGOs and other financed organizations assume their intention to do good is sufficient to achieve social change, a more enabling normative environmen and prevent harm. The risk is clear, approaches not grounded in hybridity inequities in the short and long term a may sustain uneven power dynamics.

Ethical thinking during the community assessment and project design phase
should involve defining a set of shared values that the intervention designers and the local communities may have. These values can guide discussions on what an NSI seeks to do and how it will do this. Designers should create spaces to engage community members in the design phase, in strategic decisionmaking during the definition of key project strategies. This is important, as it will lead to a more equal footing between the designers and the local communities and will ensure that
taken into account.
Defining a shared set of values can guide what decisions are made vis-a-vis emerging social changes throughout the NSI implementation cycle.

\section{HOW TO MITIGATE}

\section{SOCIAL PUSHBACK}

In the process of norms-shifting, social

pushback often occurs. Vaccine hesitators,

for example, may threaten health care

workers doing vaccinations or they might

refuse other prevention strategies such

as mask wearing. On the other hand,

communities may take off with

as neighbourhood

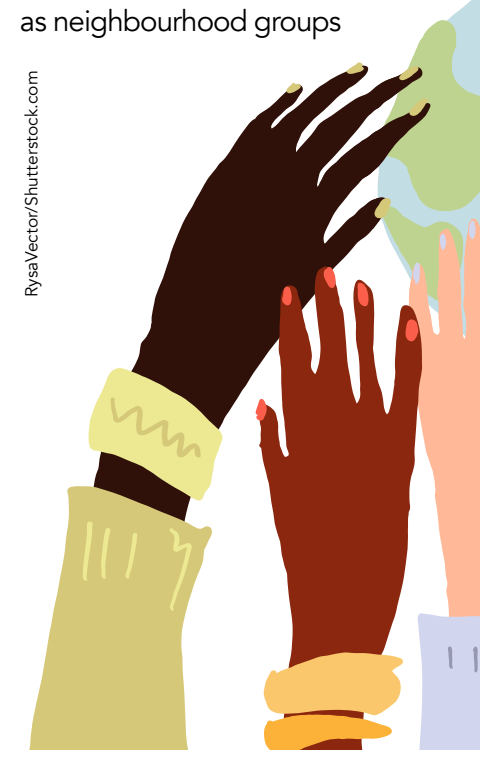
new effects of social change processes.
As new issues emerge, returning to project values can be helpful during the decision-

making process of how to support or mitigate in ethically considered ways the It is important to understand the local context within which specific social values perate, otherwise, actions viewed as the generation of lead to the generation of new
of inequalities.

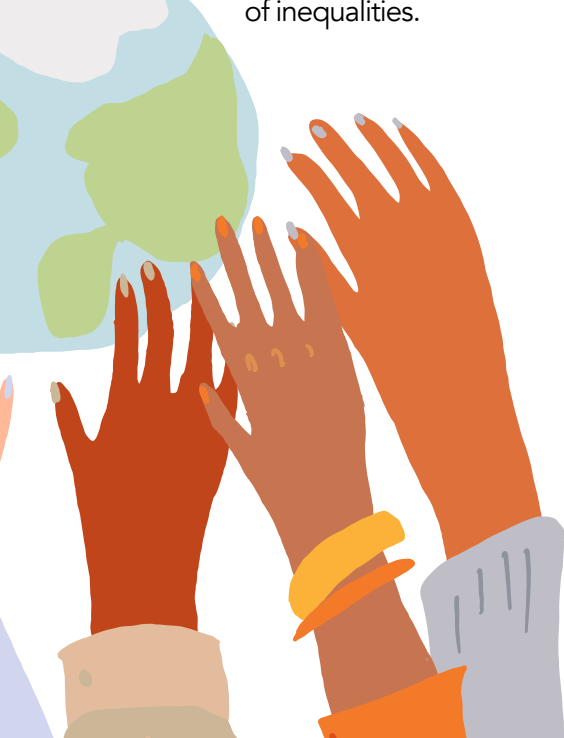

\section{Behind the Research}
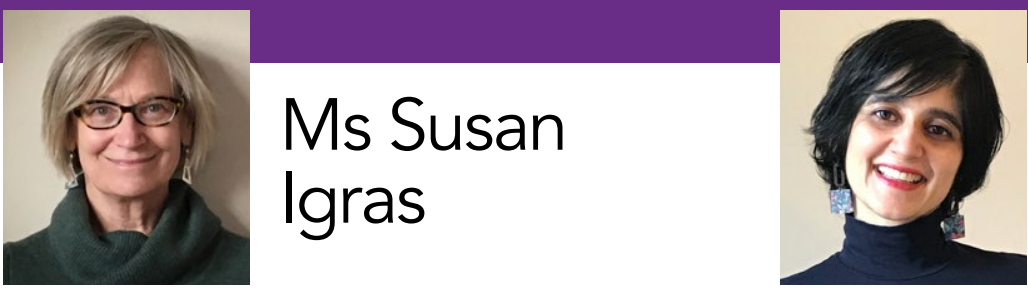

Dr Anjalee Kohli

E: smi6@georgetown.edu E: ak1684@georgetown.edu W: https://irh.org/projects/passages/ W: https://gucchd.georgetown.edu/ W: www.alignplatform.org/resources?keywords=learning+collaborative

\section{Research Objectives}

Igras and Kohli propose ten values that can guide partnership, dialogue and decision-making for normsshifting interventions (NSI). These values address gender and other social inequalities which prevent people from achieving health and well-being.

\section{Detail}

\section{Address}

Institute for Reproductive Health

Georgetown

Bio

Susan Igras, MPH, is a Research Instructor with Georgetown University. She is a program designer/implementation

researcher working with NGOs and Ministries on

community-based, social change initiatives and linkages

to health systems in West Afica and the Sahel. Igras is

committed to meaningful participatory processes leading to improved programs.

Anjalee Kohli, PhD, is an Assistant Professor with Georgetown University. She is an applied researcher working on gender-based violence, reproductive health and nder norms in sub-Saharan Africa and Sou 作 values-based partnerships.

Funding

- Passages Projec

Collaborators

- Paul Bukuluki

- Beniamino Cislaghi

- Sonali Khan

Institute for Reproductive Health Georgetown University Center for
Child and Human Development

\section{References}

Igras, S., Kohli, A., Bukuluki, P., Cislaghi, B., Khan, S. \& Tier, C. (202). Bringing ethical thinking to social change initiatives: Why it matters. Global Public Health. Avaliable at:
https://doi.org/10.1080/17441692.2020.1820550 Fawcett, S. (1991). Some values guiding community research and action. Journal of Applied Behavior Analysis, 24(4)

Legros, S., \& Cislaghi, B. (2020). Mapping the socialnorms literature: An overview of reviews. Perspectives on Psychological Acience, 1 (1)
org/10.1177/1745691619866455

Mackie, G., Moneti, F., Shakya, H., \& Denny, E. (2015). What of California, San Diego Center on Global Justice. https://www.unicef.org/protection/files/4 09 30 30 Whole What_are_Social_Norms.pdf

Miller, D. T., \& Prentice, D. A. (2016). Changing norms to change behavior. Annual Review of Psychology, 67(1), 339361. https://doi.org/10.1146/annurev-psych-010814-015013 Thornton, L. F. (2019). The complexity of ethical thinking and decision making (Part 1). Leading in Context [online]. Available at: httpps://leadingincontext.com/2019/07/31/the-col
of-ethical-thinking-and-decision-making-part-1/

\section{Personal Response}

What inspired you to conduct this research?

II Susan: For me, it was the accumulation of NGO experiences addressing social determinants of health. While NGO projects were aligned with government
and donor policies, for example addressing the socially and donor policies, for example addressing the socially
condoned practice of female genital cutting, communities might disagree on project designs and strategies yet had limited voice to suggest changes. How outsider projects subsequently responded was uneven.

Anjalee: For me, it was the years of witnessing unequal organizations at the expense of local communitis' well-being. Frequently, community members and local organizations were expressing frustration and suggesting different program strategies or priorities without being
taken seriously. 